\title{
Review
}

\section{Light Therapy and Alzheimer's Disease and Related Dementia: Past, Present, and Future}

\author{
Nicholas Hanford ${ }^{\mathrm{a}}$ and Mariana Figueiro ${ }^{\mathrm{b}, *}$ \\ ${ }^{a}$ Department of Communication and Media, Rensselaer Polytechnic Institute, Troy, NY, USA \\ ${ }^{\mathrm{b}}$ Lighting Research Center, Rensselaer Polytechnic Institute, Troy, NY, USA
}

Accepted 2 October 2012

\begin{abstract}
Sleep disturbances are common in persons with Alzheimer's disease or related dementia (ADRD), resulting in a negative impact on the daytime function of the affected person and on the wellbeing of caregivers. The sleep/wake pattern is directly driven by the timing signals generated by a circadian pacemaker, which may or may not be perfectly functioning in those with ADRD. A 24-hour light/dark pattern incident on the retina is the most efficacious stimulus for entraining the circadian system to the solar day. In fact, a carefully orchestrated light/dark pattern has been shown in several controlled studies of older populations, with and without ADRD, to be a powerful non-pharmacological tool to improve sleep efficiency and consolidation. Discussed here are research results from studies looking at the effectiveness of light therapy in improving sleep, depression, and agitation in older adults with ADRD. A 24-hour lighting scheme to increase circadian entrainment, improve visibility, and reduce the risk of falls in those with ADRD is proposed, and future research needs are discussed.
\end{abstract}

Keywords: Alzheimer's disease, circadian rhythm, lighting design, light therapy, sleep, wayfinding

\section{INTRODUCTION}

Alzheimer's disease and related dementia (ADRD) is the most common mental disorder diagnosed in elderly Americans, with an estimated 5.1 million people afflicted in 2010 [1]. Behavioral symptoms such as disturbed sleep-wake patterns, nocturnal wandering, agitation, and physical or verbal abuse are among the most prevalent reasons why individuals with ADRD transition to more controlled environments. Abnormal sleep patterns tend to increase with the progression of ADRD and are associated with caregiver stress from disturbed sleep as well as with patient agressive behavior during the day. Because of this, research has aimed at treating symptoms, particularly with non-

*Correspondence to: Mariana G. Figueiro, PhD, Lighting Research Center, Rensselaer Polytechnic Institute, 21 Union Street, 3rd Floor, Troy, NY 12180, USA. Tel.: +1 518687 7100; Fax: +1 518687 7120; E-mail: figuem@rpi.edu. pharmacological options due to a low risk of side effects.

\section{Circadian rhythms}

Most species on the planet endogenously generate circadian rhythms, which are constantly aligned with the environment by factors that are external to the body, mainly light/dark patterns reaching the back of the eye. In mammals, circadian rhythms are generated and regulated by an internal biological clock located in the suprachiasmatic nuclei $(\mathrm{SCN})$ of the hypothalamus of the brain. The biological clock in humans has a natural period that is slightly greater than 24 hours, and environmental cues, such as light/dark cycles (strongest time giver), social activities, and meal times, can reset and synchronize the clock daily, ensuring that our behavioral and physiological rhythms are synchronized with the external environment [2]. As diurnal species, humans who are synchronized to the 
24-hour solar day are typically awake during daytime hours and asleep during nighttime hours. Light can phase advance or phase delay human circadian rhythms, depending upon when it is applied [3]. For example, light that is applied before the minimum core body temperature, which is reached approximately 1.5 to 2.5 hours before we naturally awaken, will delay the timing of the biological clock (e.g., one will wake up later the following day), and light applied after minimum core body temperature is reached will advance the timing of the biological clock (e.g., one will wake up earlier the following day).

\section{Lighting characteristics affecting circadian rhythms}

The formal definition of light as described by the Illuminating Engineering Society of North America (IESNA) is "radiant energy that is capable of exciting the human retina and creating a visual sensation" [4]. The neural machinery in the mammalian retina provides light information to both the visual and circadian systems, but the two systems process optical radiation (light) differently [5]. Rods, cones, and a newly discovered photoreceptor, the intrinsically photosensitive retinal ganglion cells (ipRGCs) [6], participate in circadian phototransduction (how the retina converts light signals into neural signals for the biological clock). The quantity of polychromatic "white" light necessary to activate the circadian system is at least two orders of magnitude greater than the amount that activates the visual system. The circadian system is maximally sensitive to short-wavelength ("blue") light, with a peak spectral sensitivity at around $460 \mathrm{~nm}$, while the fovea is most sensitive to the middle-wavelength portion of the visible spectrum, peaking at around $555 \mathrm{~nm}$. Operation of the visual system does not depend significantly on the timing of light exposure, and thus responds well to a light stimulus at any time of the day or night. On the other hand, the circadian system is dependent on the timing of light exposure, as discussed above. In addition, while the visual system responds to a light stimulus very quickly (in milliseconds), the duration of light exposure needed to affect the circadian system can take minutes. For the visual system, spatial light distribution is critical for good visibility. It is not yet well-established how light incident on different portions of the retina affects the circadian system. It is also important to note that the short-term history of light exposure affects the sensitivity of the circadian system to light; the higher the exposure to light during the day, the lower the sensitivity of the circadian system to light, as measured by nocturnal melatonin suppression and phase shifting.

\section{Light and the aging circadian system}

Studies of the biological clock have shown a reduced neuronal activity in the SCN of the elderly, especially after the age of 80 [7], and reduced circadian rhythm amplitude after the age of 50 [8]. This suggests that, at a molecular level, the SCN becomes less responsive to entrainment stimuli such as light-induced neural signals from the retina. Further, it is suggested that some of the neural processes involved in the entrainment process might be dysfunctional or less effective as we age [9]. Light information travels from the retina to the SCN through the retinohypothalamic tract. Disturbances in circadian rhythms leading to poor sleep in older adults can be the result of dysfunctional circadian pathways or a pathway that cannot process light information with as much fidelity. Also, the first stage of phototransduction (when light signals are converted into neural signals) is negatively affected: older adults not only have reduced optical transmission at short wavelengths, which is maximally effective for the circadian system, they also lead a more sedentary indoor lifestyle, with less access to bright light during the day [10-13], potentially increasing the risk for circadian disruption. In fact, Figueiro et al. measured, using a calibrated light-measuring device, circadian light exposures in healthy older adults and in persons with ADRD during two seasons (fall/winter and spring/summer). Using the metrics calculated from light/dark and activity/rest patterns collected over 5 consecutive days, they demonstrated that persons with ADRD are more disrupted than healthy older adults and that this circadian disruption is more pronounced during winter months, when there is less daylight availability [14].

Finally, changes in the amplitude and timing of melatonin and core body temperature, both output rhythms of the biological clock, may occur in older adults. Melatonin is a hormone produced at night and in darkness and is believed to be a timing messenger to the body, indicating to all cells that it is circadian night. Lower amplitudes of melatonin rhythms may be associated with reduced sleep efficiency and deterioration of internal circadian rhythms, affecting hormone production, alertness, and performance [15]. Furthermore, earlier timing of peak of melatonin rhythms may induce earlier drops in core body temperature, resulting in early wake times (reviewed in [16]). These changes in biological markers, closely associated with the 
biological clock, may be a result of deterioration of the functioning of the biological clock as a result of the disease.

\section{SLEEP DISTURBANCES, BEHAVIOR AND MOOD IN PERSONS WITH ADRD}

\section{Sleep disturbances}

Sleep disturbances are among the more common neurobehavioral symptoms of ADRD. An increased tendency to fall asleep during the daytime, together with increased wakefulness during the night has been demonstrated in patients with advanced but also mild to moderate ADRD [17]. Research estimates that ADRD patients will spend approximately $40 \%$ of their night awake and a large portion of the solar day asleep [18-20]. Sleep disturbances eventually become too burdensome for familial caregivers and are the leading cause of persons with ADRD institutionalization [21-24].

An indirect, negative impact of sleep disturbances is the risk of falling, which is exacerbated by disrupted circadian rhythms because persons with ADRD are more likely to wake in the middle of the night under little or no light. Often these patients get out of bed, either to use the restroom or just wander around their room. Persons with ADRD are about 3 times more likely to fall [25-27] and their recovery is generally longer than that of healthy older adults [28].

\section{Agitated behavior}

Once institutionalized, patients who suffer from the most sleep disturbances at night are likely to become aggressive during the day [29]. Sundowning — increased agitation in the late afternoon and early evening - may also contribute to aggressive behavior, and the aggression eventually leads to negative outcomes for both persons with ADRD and nursing staff; approximately $93 \%$ of nursing home residents and $42 \%$ of assisted living residents display dementia-related aggression [30-32].

\section{Depression}

A common symptom that manifests within older adults with ADRD is depression, likely because they experience greater social isolation. The American Geriatrics Society states that depression occurring simultaneously with dementia is the most common affliction for older adults in nursing homes [33].
Depression can lead to poorer health outcomes, psychological distress, and functional impairment. In addition, these depressive symptoms can place added stress on caregivers in both institutions and homes [1].

\section{LIGHTING FOR PERSONS WITH ADRD}

\section{Sleep disturbances}

Table 1 summarizes several studies [34-51] that have investigated the effects of light therapy on sleep disturbances in persons with ADRD. It is important to emphasize that almost none of the published studies utilized photometric terms or instrumentation appropriate to quantify the impact of light on the retina for circadian effectiveness.

Light levels reported in Table 1 are in photopic lux. Consequently, generalizations from these studies must remain qualitative (e.g., bright versus dim) rather than quantitative. Nevertheless, bright light exposure during the morning (typically $>1000$ lux at the cornea) has been shown to improve nighttime sleep, increase daytime wakefulness, reduce evening agitation behavior, and consolidate rest/activity patterns of people with ADRD [34, 35, 38-42, 47-51, 57]. All-day, uncontrolled exposure to $>1000$ lux at the cornea of a white light (4100 K) improved sleep efficiency and cognition in persons with ADRD as well as reduced symptoms of depression [36, 43]. Dawn-dusk simulation — a lighting system that moderates light levels according to time of day - has had some success in a 3-week trial study [46]. Evening light exposure has also been shown to be effective in consolidating rest/activity rhythms of those with ADRD and helping them to sleep better at night $[37,39,51]$. Lower levels (30 lux at the cornea) of light sources that are more tuned to the spectral sensitivity of the circadian system, such as narrowband short-wavelength (blue) light administered for 2 hours in the early evening were also shown to be effective in increasing sleep efficiency in persons with ADRD [44, 45].

\section{Agitation}

Bright light does appear to be a treatment possibility for aggressive behavior in ADRD patients. Burns et al. [52] showed improvements in Cohen-Mansfield Agitation Inventory (CMAI) and Crichton Royal Behavior Rating Scale (CRBRS) scores after 2 weeks of late morning (10:00-12:00) light therapy at 10,000 lux. Skjerve and colleagues [53] administered a bright light regimen of 5000-8000 lux for 45 minutes per day, 


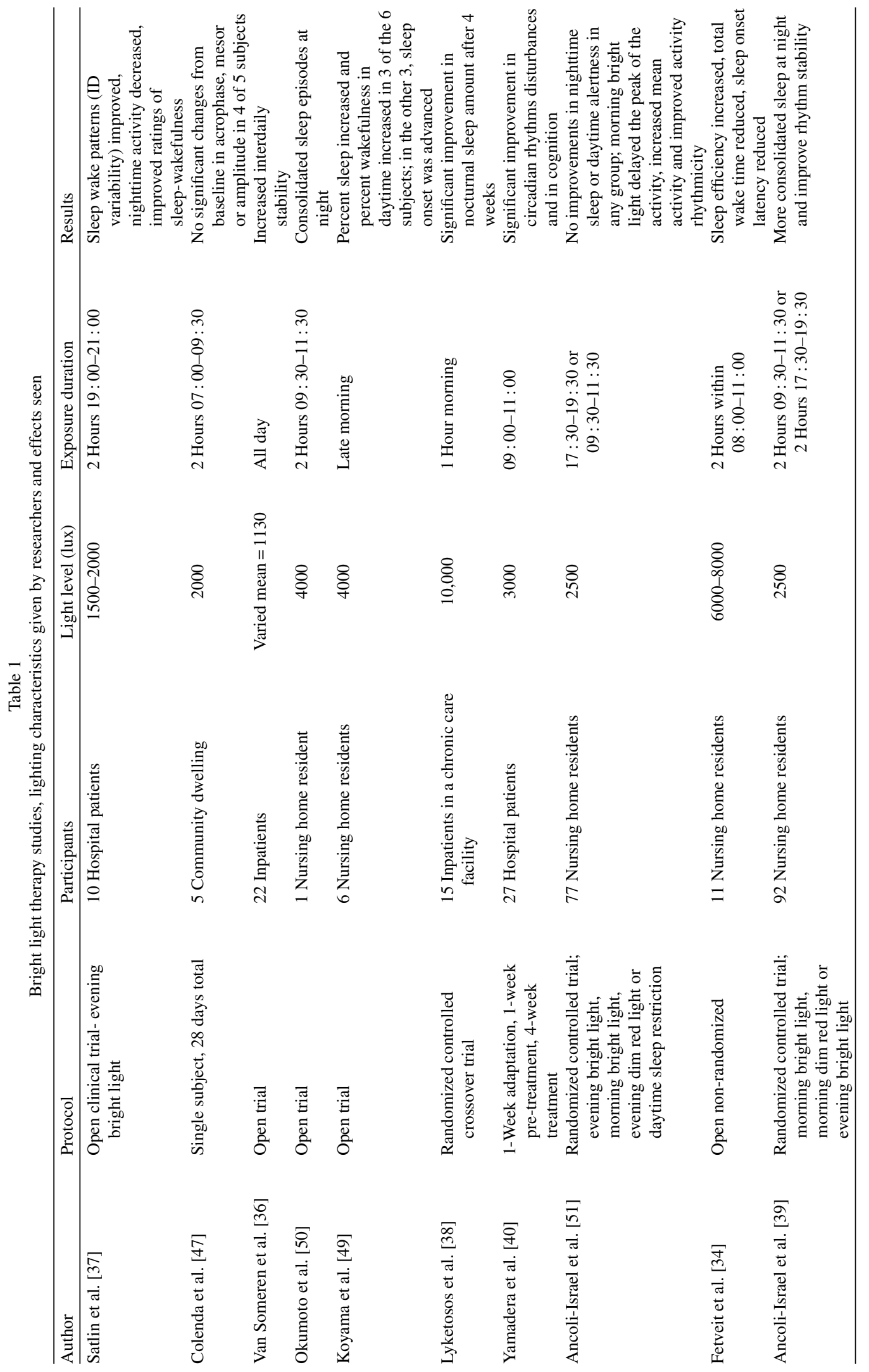




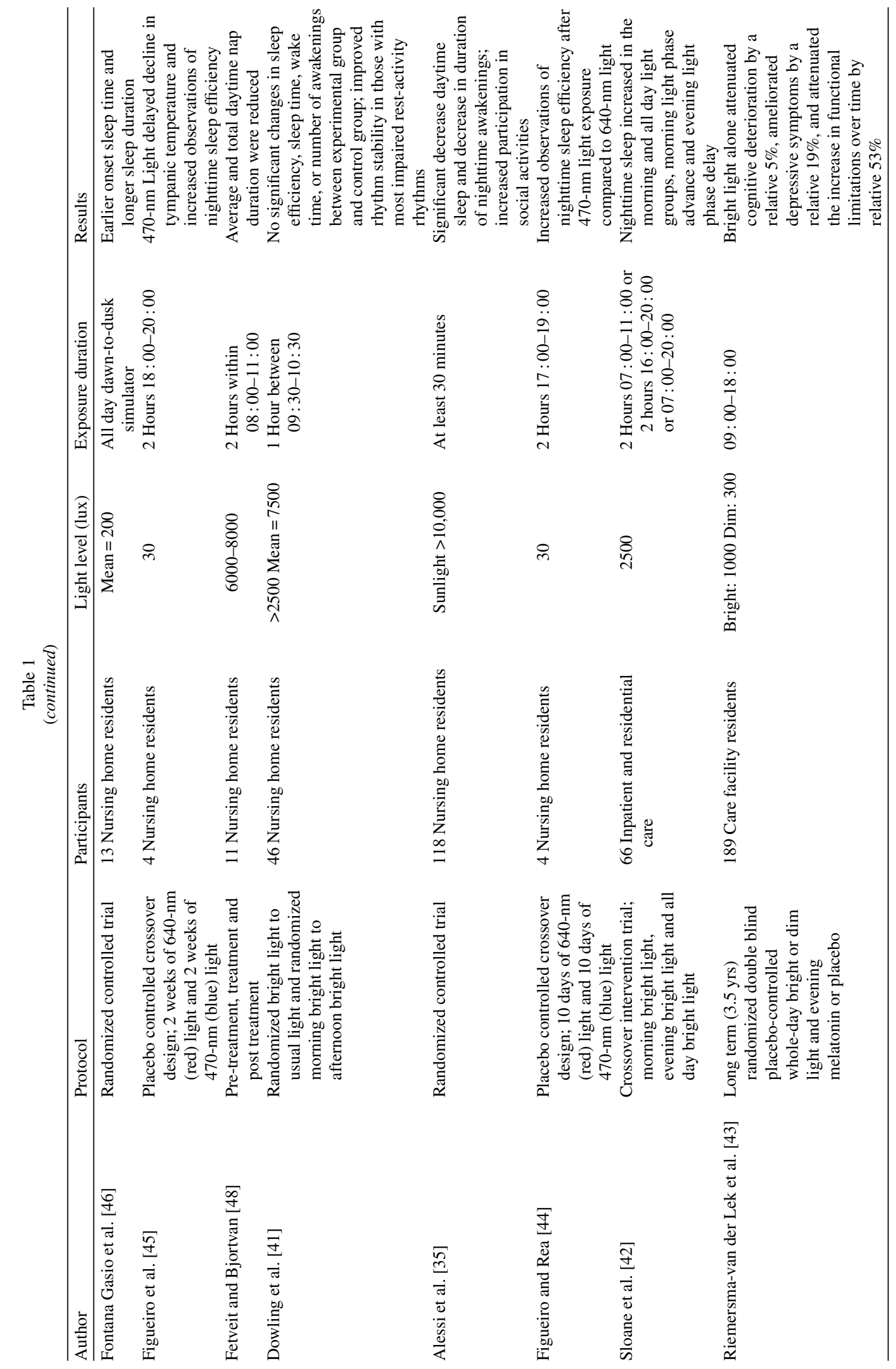


which resulted in significant improvements in CMAI and Behavior Pathology in Alzheimer's Disease Rating Scale (BEHAVE-AD) scores. Thorpe et al. [54] also showed that 30 minutes exposure to morning light $(10,000$ lux at the cornea) improved CMAI scores. It is suggested that the impact of light on reducing CMAI scores may be greater in those who have higher CMAI scores [55]. The effects of light therapy on agitation were also shown in those with vascular dementia, the second most common type of dementia [56].

Dowling and colleagues [57] found that exposing persons with ADRD to bright light at 2500 lux at varying times of day had diverse effects on aggressive behaviors. While both morning and afternoon exposures were successful in significantly altering the levels of aggressive behaviors, specifically agitation, depression, aberrant motor behavior, and appetite, the timing of treatment was of great importance in the outcome of treatment. Morning light exposure was shown to be more effective than afternoon light exposure in this case. Haffmans et al. [58], with a regimen of morning light therapy (30 minutes, between 08:00 and 11:00, from a 10,000 lux light box), improved motor restlessness in ADRD patients.

\section{Depression}

While positive effects of light therapy have been shown in some cases of depression [59, 60], mixed results have come with the attempt to treat depression symptoms in ADRD patients with light therapy.

In their long-term study, Riemersma-van der Lek and colleagues [43] showed a significant improvement in Cornell Scale for Depression in Dementia (CSDD) scores over an average length of 15 months of light therapy. Likewise, Hickman and colleagues [61] showed a positive effect for female ADRD patients when treated with morning bright light (2000-2500 lux), but researchers also believed that patients with higher CSDD scores were necessary for a better understanding of the influences of light therapy on depression.

\section{Risk of falls}

Figueiro et al. [62, 63] proposed a novel night lighting approach to the living environment that could improve postural control and stability. They showed in a series of studies that the use of strips of LEDs placed around a doorframe, providing vertical and horizontal cues, decreased sway and reduced weight transfer time compared to having a typical nightlight providing dim lighting in the environment. In another study, Figueiro et al. [64] found that the addition of pathway lights to an environment lit with dim light from an incandescent nightlight increased velocity and decreased step length variability during walking.

\section{PROPOSED 24-HOUR LIGHTING SCHEME}

Figueiro [65] proposed, based on theoretical knowledge about how light impacts aging vision, circadian and perceptual systems, a 24-hour lighting scheme that is designed to provide: a) high circadian stimulation during the day and low circadian stimulation at night, b) good visual conditions during waking hours, and c) nightlights that are safe and minimize sleep disruption. It was proposed that high circadian stimulation be provided by 1000 lux or higher at the cornea from a circadian-effective white light source for at least 2 hours during the day. If longer exposures of light are planned, light levels may be reduced to no less than 600 lux at the cornea from the same circadian-effective white light source. No more than 60 lux at the cornea of a circadian-ineffective white light source (e.g., $2700 \mathrm{~K}$ compact fluorescent lamp or LEDs) is recommended for general lighting in the evening hours.

Although the exact amount of light needed to impact the circadian systems of those with ADRD is not known, it is possible to theoretically compare a variety of practical light sources in terms of their ability to provide a criterion response by the circadian system (50\% nocturnal melatonin suppression) for a fixed, small pupil size (2.3 mm diameter), as shown in Table 2 [66]. It should also be noted that the relationship between melatonin suppression and consolidation of rest/activity rhythms remains unclear. Since commercially available light meters are always calibrated in terms of the photopic luminous efficiency function, the levels of photopic illuminance needed at the eye are used as the measure of the amount of light needed to reach the criterion response. It is worth noting that under natural viewing conditions, pupil size can be larger than $2.3 \mathrm{~mm}$ in diameter, so a lower level of illuminance would be needed to reach this criterion level of melatonin suppression. Generally then, for light sources providing the same photopic light level, the greater the proportion of short-wavelength (visible) radiation from the source, the more effective it will be for stimulating the human circadian system. More importantly, although there is no compelling reason to assume that acute melatonin suppression and phase shifting of the timing of the biological clock respond 
Table 2

Photopic illuminance to achieve 50\% melatonin suppression. Several practical light sources with the required photopic illuminance (lux, or $1 \mathrm{~m} / \mathrm{m}^{2}$ ) levels at the eye, having a fixed pupil diameter of $2.3 \mathrm{~mm}$, for $50 \%$ nocturnal melatonin suppression after one hour exposure (adapted from [66]). Although the absolute numbers will vary depending on pupil area, duration of exposure, exact spectral power distribution of the light source, distance from the source, the numbers in Table 2 can be used to determine the relative effectiveness of these different light sources as it may impact acute melatonin suppression, one marker of the biological clock. Whether or not these values are the same for estimating phase shifting of the timing of the biological clock by these light sources is still not established

\begin{tabular}{lc}
\hline Light source & Illuminance (lux) \\
\hline 2700 K compact fluorescent & 1220 \\
$\quad$ (Greenlite15WELS-M) & \\
2856 K incandescent A lamp & 1180 \\
3350 K linear fluorescent (GE F32T8 SP35) & 1070 \\
4100 K linear fluorescent (GE F32T8 SP41) & 430 \\
5200 K LED phosphor white (Luxeon Star) & 550 \\
6220 K linear fluorescent (Philips Colortone 75) & 610 \\
8000 K fluorescent (OSRAM Sylvania Lumilux & \\
$\quad$ Skywhite) & 50 \\
Blue LED (Luxeon Rebel, $\lambda$ max $=470$ nm) & 525 \\
Daylight (CIE D65) & \\
\hline
\end{tabular}

differently to a light stimulus, it is important to keep in mind that the calculations presented in Table 2 are based on studies where only acute melatonin suppression was measured.

Further research should be conducted to determine minimum light levels needed to impact the circadian systems of those with ADRD and to verify how the estimations presented in Table 2 affect rest/activity patterns in those with ADRD. More importantly, it is not known how light levels can be reduced with increased duration of exposure. It has been shown in a 2-week light treatment study that delivering $30 \mathrm{~min}$ utes of a bright white light (4200 lux) in the morning to memory-impaired older adults and their caregivers improved sleep and mood in caregivers, but diminished sleep in those with memory impairment [67]. It has been suggested that light therapy's effect on sleep in those with ADRD is only measurable after 6 months of treatment possibly because these patients are slower to respond to the stimulus [43].

Daylight from windows and clerestories is a circadian-effective light source, but it should not be assumed that there will always be enough circadian stimulation from daylight in architectural spaces [68]. Daylight levels in the room drop quickly as the distance from the window increases; 3-4 meters away from a window, daylight levels are quite low, even on a sunny day. It should be noted too that if sunlight from the window penetrates the room, discomfort glare will cause occupants to draw blinds or shades, eliminating daylight entirely from the space.

If energy consumption is a constraint, the architect can either select specific spaces to implement the proposed lighting scheme or follow a scheme similar to the one used in the experiments by Figueiro et al. $[44,45]$ by providing another layer of blue light in the morning. Portable luminaires providing diffuse blue light from LEDs $\left(\lambda_{\max }=470 \mathrm{~nm}\right)$ can be placed on dining tables, around television screens, or attached to wheelchairs. It is not known, however, how successful compliance with these light delivery methods will be and how acceptable this kind of light source will be to users.

Good visual conditions for waking hours can be provided by lighting that is high, on the task, glare-free with no direct or reflected view of the light source, with softer shadows throughout the space with balanced illuminance levels, and with good color rendering characteristics [69].

Just as important, the proposed 24-hour lighting scheme should provide nightlights that reduce the risk of falls and help maintain sleep. Figueiro [65] proposed the use of nightlights that provide visual information about the local environment (5 to 10 lux at the cornea) as well as perceptual information that enables the residents to orient [62-64]. The proposed nightlights accent the rectilinear architectural features in the room as well as accentuate horizontal pathways to the bathroom. The use of motion sensors with dim nightlights eliminates the need to find switches in the dark and helps residents to remain asleep when caregivers enter the room. The use of low light levels allows older people to navigate through the space safely without disrupting their sleep. This proposed novel nightlighting system needs to be tested in persons with ADRD and installed in the field, but it has promising features to help reduce the risk of falls in those with ADRD.

\section{CONCLUSIONS}

\section{Past}

Persons with ADRD exhibit random patterns of rest and activity rather than the consolidated sleep/wake cycle found in healthy, older adults. This lack of sleep consolidation is one of the main reasons why they are institutionalized. Light therapy has been shown to improve rest/activity rhythms and sleep efficiency in persons with ADRD in some, but not all, studies, presumably through consolidation of their circadian rhythms. 


\section{Present}

While additional research is still needed to test the effectiveness of a 24-hour lighting scheme on vision, circadian regulation, and the risk of falls in older adults with ADRD, it must be true that the proposed lighting scheme discussed here will provide a better light/dark pattern for the circadian system than the dim unvarying ones commonly found in senior care facilities.

\section{Future}

Positive results can be obtained, however, if thoughtful, quantitative lighting solutions based upon basic principles of circadian regulation are designed while still paying attention to maintaining good vision and safety while awake and minimizing sleep disruption at night.

\section{ACKNOWLEDGMENTS}

The authors would like to acknowledge Michael D. Shmerling and Chris Brown of Abe's Garden Alzheimer's and Memory Care of Excellence, and the National Institute on Aging (grant \# R01AG034157) for providing funding to prepare this manuscript and the work presented here. Barbara Plitnick, Dennis Guyon, and Rebekah Mullaney of the Lighting Research Center are acknowledged for their contributions to the manuscript.

Authors' disclosures available online (http://www.jalz.com/disclosures/view.php?id=1537).

\section{REFERENCES}

[1] About Alzheimer's Disease: Alzheimer's Basics, National Institute on Aging, http://www.nia.nih.gov/ alzheimers/topics/alzheimers-basics, Accessed on July 26, 2012.

[2] Moore RY (1997) Circadian rhythms: Basic neurobiology and clinical applications. Апnи Rev Med 48, 253-266.

[3] Khalsa SBS, Jewett ME, Cajochen C, Czeisler CA (2003) A phase response curve to single bright light pulses in human subjects. J Physiol 15, 945-952.

[4] Rea MS (2000) The IESNA lighting handbook: Reference \& application. IESNA Publ. Dep., New York, NY.

[5] Rea MS, Figueiro MG, Bullough JD (2002) Circadian photobiology: An emerging framework for lighting practice and research. Lighting Res Technol 34, 177-187.

[6] Berson DM, Dunn FA, Takao M (2002) Phototransduction by retinal ganglion cells that set the circadian clock. Science $\mathbf{2 9 5}$, 1070-1073.

[7] Swaab D, Fliers E, Partiman T (1985) The suprachiasmatic nucleus of the human brain in relation to sex, age and senile dementia. Brain Res 342, 37-44.
[8] Hofman MA, Swaab DF (2006) Living by the clock: The circadian pacemaker in older people. Ageing Res Rev 5, 33-51.

[9] Skene DJ, Swaab DF (2003) Melatonin rhythmicity: Effect of age and Alzheimer's disease. Exp Gerontol 38, 199-206.

[10] Shochat T, Martin J, Marler M, Ancoli-Israel S (2000) Illumination levels in nursing home patients: Effects on sleep and activity rhythms. J Sleep Res 9, 373-379.

[11] Campbell SS, Kripke DF, Gillin JC, Hrubovcak JC (1988) Exposure to light in healthy elderly subjects and Alzheimer's patients. Physiol Behav 42, 141-144.

[12] Espiritu RC, Kripke DF, Ancoli-Israel S, Mowen MA, Mason WJ, Fell RL, Klauber MR, Kaplan OJ (1994) Low illumination experienced by San Diego adults: Association with atypical depressive symptoms. Soc Biol Psych 35, 403-407.

[13] Sanchez R, Ge Y, Zee P (1993) A comparison of the strength of external zeitgeber in young and older adults. Sleep Res $\mathbf{2 2}$, 416.

[14] Figueiro MG, Hamner R, Higgins P, Hornick T, Rea MS (2012) Field measurements of light exposures and circadian disruption in two populations of older adults. J Alzheimers Dis 31, 711-715.

[15] Karasek M (2004) Melatonin, human aging, and age-related diseases. Exp Gerontol 39, 1723-1729.

[16] Van Someren EJ (2000) Circadian rhythms and sleep in human aging. Chronobiol Int 17, 233-243.

[17] Bonanni E, Maestri M, Tognoni G, Fabbrini M, Nucciarone B, Manca ML, Gori S, Iudice A, Murri L (2005) Daytime sleepiness in mild and moderate Alzheimer's disease and its relationship with cognitive impairment. J Sleep Res 14, 311317.

[18] Ancoli-Israel S, Parker L, Sinaee R, Fell RL, Kripke DF (1989) Sleep fragmentation in patients from a nursing home. J Gerontol 44, M18-M21.

[19] Vitiello MV, Poceta JS, Prinz PN (1991) Sleep in Alzheimer's disease and other dementing disorders. Can J Psychol 45, 221-239.

[20] McCurry SM, Reynolds CF, Ancoli-Israel S, Teri L, Vitiello MV (2000) Treatment of sleep disturbance in Alzheimer's disease. Sleep Med Rev 4, 603-628.

[21] Pollak CP, Perlick D (1991) Sleep problems and institutionalization of the elderly. J Geriatr Psychiatry Neurol 4, 204-210.

[22] Hope T, Keene J, Fairburn C, McShane R, Jacoby R (1997) Behaviour changes in dementia 2: Are there behavioural syndromes? Int J Geriatr Psychiatry 12, 1074-1078.

[23] Hope T, Keene J, Gedling K, Cooper S, Fairburn C, Jacoby $\mathrm{R}$ (1997) Behaviour changes in dementia 1: Point of entry data of a prospective study. Int J Geriatr Psychiatry 12, 10621073.

[24] Yaffe K, Fox P, Newcomer R, Sands L, Lindquist K, Dane $\mathrm{K}$, Covinsky KE (2002) Patient and caregiver characteristics and nursing home placement in patients with dementia. JAMA 287, 2090-2097.

[25] Shaw FE, Kenny RA (1998) Can falls in patients with dementia be prevented? Age Ageing 27, 7-9.

[26] Tinetti ME, Speechley M, Ginter SF (1988) Risk factors for falls among elderly persons living in the community. $\mathrm{N} \mathrm{Engl}$ J Med 319, 1701-1707.

[27] Buchner DM, Larson EB (1987) Falls and fractures in patients with Alzheimer-type dementia. JAMA 257, 1492-1495.

[28] Allan LM, Ballard CG, Rowan EN, Kenny RA (2009) Incidence and prediction of falls in dementia: A prospective study in older people. PLOS ONE 4, e5521.

[29] Cohen-Mansfield J, Werner P, Freedman L (1995) Sleep and agitation in agitated nursing home residents: An observational study. Sleep 18, 674-680. 
[30] Cohen-Mansfield J, Billig N (1986) Agitated behaviors in the elderly. I. A conceptual review. J Am Geriatr Soc 34, 711721.

[31] Burgio L, Leon J (1997) Using patient and proxy reports as outcome measures in Alzheimer disease research. Alzheimer Dis Assoc Disord 11, 179-180.

[32] Gruber-Baldini AL, Boustani M, Sloane PD, Zimmerman S (2004) Behavioral symptoms in residential care/assisted living facilities: Prevalence, risk factors, and medication management. J Am Geriatr Soc 52, 1610-1617.

[33] American Geriatrics Society, American Association for Geriatric Psychiatry (2003) The American Geriatrics Society and American Association for Geriatric Psychiatry Recommendations for Policies in Support of Quality Mental Health Care in U.S. Nursing Homes. J Am Geriatr Soc 51, 12991304.

[34] Fetveit A, Skjerve A, Bjorvatn B (2003) Bright light treatment improves sleep in institutionalised elderly-an open trial. Int J Geriatr Psychiatry 18, 520-526.

[35] Alessi CA, Martin JL, Webber AP, Cynthia Kim E, Josephson KR (2005) Randomized, controlled trial of a nonpharmacological intervention to improve abnormal sleep/wake patterns in nursing home residents. J Am Geriatr Soc 53, 803-810.

[36] Van Someren E, Kessler A, Mirmiran M, Swaab DF (1997) Indirect bright light improves circadian rest-activity rhythm disturbances in demented patients. Biol Psychiatry 41, 955963.

[37] Satlin A, Volicer L, Ross V, Herz L, Campbell S (1992) Bright light treatment for behavioral and sleep disturbances in patients with Alzheimer's disease. Am J Psychiatry 149, 1028-1032.

[38] Lyketosos C, Lindell Veiel L, Baker A, Steele C (1999) A randomized, controlled trial of bright light therapy for agitated behaviors in dementia patients residing in long-term care. Int J Geriatr Psychiatry 14, 520-525.

[39] Ancoli-Israel S, Gehrman P, Martin JL, Shochat T, Marler M, Corey-Bloom J, Levi L (2003) Increased light exposure consolidates sleep and strengthens circadian rhythms in severe Alzheimer's disease patients. Behav Sleep Med 1, 22-36.

[40] Yamadera H, Ito T, Suzuki H, Asayama K, Ito R, Endo S (2000) Effects of bright light on cognition and sleep-wake (circadian) rhythms disturbances in Alzheimer-type dementia. Psychiatry Clin Neurosci 54, 352-353.

[41] Dowling GA, Hubbard EM, Mastick J, Luxenberg JS, Burr RL, Van Someren EJW (2005) Effect of morning bright light treatment for rest-activity disruption in institutionalized patients with severe Alzheimer's disease. Int Psychogeriatr 17, 221-236.

[42] Sloane PD, Williams CS, Mitchell CM, Preisser JS, Wood W, Barrick AL, Hickman SE, Gill KS, Connell BR, Edinger J, Zimmerman S (2007) High-intensity environmental light in dementia: Effect on sleep and activity. J Am Geriatr Soc 55, 1524-1533.

[43] Riemersma-van der Lek RF, Swaab DF, Twisk J, Hol EM, Hoogendijk WJ, Van Someren EJ (2008) Effect of bright light and melatonin on cognitive and noncognitive function in elderly residents of group care facilities: A randomized controlled trial. JAMA 299, 2642-2655.

[44] Figueiro MG, Rea MS (2005) LEDs: Improving the sleep quality of older adults. In Proceedings of the CIE Midterm Meeting and International Lighting Congress, Leon, Spain.

[45] Figueiro MG, Eggleston G, Rea MS (2003) Light therapy and Alzheimer's disease. Sleep Rev 4, 24.

[46] Fontana Gasio P, Kräuchi K, Cajochen C, Van Someren E, Amrhein I, Pache M, Savaskan E, Wirz-Justice A (2003)
Dawn-dusk simulation light therapy of disturbed circadian rest-activity cycles in demented elderly. Exp Gerontol 38, 207-216.

[47] Colenda CC, Cohen W, McCall WV, Rosenquist PB (1997) Phototherapy for patients with Alzheimer disease with disturbed sleep patterns: Results of a community-based pilot study. Alzheimer Dis Assoc Disord 11, 175-178.

[48] Fetveit A, Bjorvatn B (2005) Bright-light treatment reduces actigraphic-measured daytime sleep in nursing home patients with dementia: A pilot study. Am J Geriatr Psychiatry 13, 420-423.

[49] Koyama E, Matsubara H, Nakano T (1999) Bright light treatment for sleep-wake disturbances in aged individuals with dementia. Psychiatry Clin Neurosci 53, 227-229.

[50] Okumoto Y, Koyama E, Matsubara H, Nakano T, Nakamura R (1998) Sleep improvement by light in a demented aged individual. Psychiatry Clin Neurosci 52, 194-196.

[51] Ancoli-Israel S, Martin JL, Kripke DF, Marler M, Klauber MR (2002) Effect of light treatment on sleep and circadian rhythms in demented nursing home patients. J Am Geriatr Soc 50, 282-289.

[52] Burns A, Allen H, Tomenson B, Duignan D, Byrne J (2007) Bright light therapy for agitation in dementia: A randomized controlled trial. Int Psychogeriatrics 21, 711.

[53] Skjerve A, Holsten F, Aarsland D, Bjorvatn B, Nygaard HA, Johansen IM (2004) Improvement in behavioral symptoms and advance of activity acrophase after short-term bright light treatment in severe dementia. Psychiatry Clin Neurosci 58, 343-347.

[54] Thorpe L, Middleton J, Russell G, Stewart N (2000) Bright light therapy for demented nursing home patients with behavioral disturbance. Am J Alzheimer's Dis 15, 18-26.

[55] Lovell BB, Ancoli-Israel S, Gevirtz R (1995) Effect of bright light treatment on agitated behavior in institutionalized elderly subjects. Psychiatry Res 57, 7-12.

[56] Mishima K, Hishikawa Y, Okawa M (1998) Randomized, dim light controlled, crossover test of morning bright light therapy for rest-activity rhythm disorders in patients with vascular dementia and dementia of Alzheimer's type. Chronobiol Int 15, 647-654

[57] Dowling GA, Graf CL, Hubbard EM, Luxenberg JS (2007) Light Treatment for Neuropsychiatric Behaviors in Alzheimer's Disease. West J Nurs Res 29, 961-975.

[58] Haffmans PM, Sival RC, Lucius SA, Cats Q, van Gelder L (2001) Bright light therapy and melatonin in motor restless behaviour in dementia: A placebo-controlled study. Int $J$ Geriatr Psychiatry 16, 106-110.

[59] Tuunainen A, Kripke DF, Endo T (2004) Light therapy for non-seasonal depression. Cochrane Database Syst Rev 2, CD004050.

[60] Martiny K, Lunde M, Undén M, Dam H, Bech P (2005) Adjunctive bright light in non-seasonal major depression: Results from clinician-rated depression scales. Acta Psychiatr Scand 112, 117-125.

[61] Hickman SE, Barrick AL, Williams CS, Zimmerman S, Connell BR, Preisser JS, Mitchell CM, Sloane PD (2007) The effect of ambient bright light therapy on depressive symptoms in persons with dementia. J Am Geriatr Soc 55, 1817-1824.

[62] Figueiro M, Gras L, Qi R, Rizzo P, Rea M, Rea M (2008) A novel night lighting system for postural control and stability in seniors. Lighting Res Technol 40, 111-126.

[63] Figueiro MG, Gras LZ, Rea MS, Plitnick B, Rea MS (2012) Lighting for improving balance in older adults with and without risk for falls. Age Ageing 41, 392-395. 
[64] Figueiro MG, Plitnick B, Rea MS, Gras LZ, Rea MS (2011) Lighting and perceptual cues: Effects on gait measures of older adults at high and low risk for falls. BMC Geriatr 11, 49.

[65] Figueiro MG (2008) A proposed $24 \mathrm{~h}$ lighting scheme for older adults. Lighting Res Technol 40, 153-160.

[66] Rea MS (2011) Human health and well-being: Promise for a bright future from solid-state lighting. In LightEmitting Diodes: Materials, Devices, and Applications for Solid State Lighting XV. Proceedings of SPIE Volume: 7954, Streubel K, Jeon H, Tu L-W, Linder N, eds, doi: $10.1117 / 12.876409$
[67] Friedman L, Spira AP, Hernandez B, Mather C, Sheikh J, Ancoli-Israel S, Yesavage JA, Zeitzer JM (2012) Brief morning light treatment for sleep/wake disturbances in older memory-impaired individuals and their caregivers. Sleep Med 13, 546-549.

[68] Bullough JD, Rea MS, Stevens RG (1996) Light and Magnetic Fields in a Neonatal Intensive Care Unit. Bioelectromagnetics 17, 396-405.

[69] Figueiro MG (2001) Lighting the Way: A key to independence. A Guide for Older Adults. Lighting Research Center, Rensselaer Polytechnic Institute, Troy, NY. 